\title{
Socio-spatial Approaches for Media and Communication Research
}

\section{Segah Sak}

Digital media can be considered as the focus of contemporary research on media and communication. This is related not only to the significance of digital media on its own, but also to its invasion of other mass media. On the one hand, media and communication research handle a wide array of subjects such as interface design, architecture of information and communication technologies (ICT), or audience reception. On the other hand, as digital media are now part of a fundamental dynamic of contemporary culture, it is a subject of research in a wide array of disciplines.

Digital media is an issue of discussion for architectural and urban research, since spaces not only are computable through digital media, but also accommodate various forms of digital media. Although there is a significant body of works that keep their distance from digital media in the theoretical discussions of the concepts of space and place, most of the research on socio-spatial issues, particularly human geography, handles digital media and communication technologies as a fundamental part of contemporary urban space and life. In the meantime, media and communication research has almost always been inclusive of spatial issues. Especially after William Gibson developed the concept of cyberspace in his

\footnotetext{
S. Sak $(\bowtie)$

Bilkent University, Ankara, Turkey

e-mail: segah@bilkent.edu.tr

(C) The Author(s) 2016

S. Kubitschko, A. Kaun (eds.), Innovative Methods in Media and

Communication Research, DOI 10.1007/978-3-319-40700-5_4
} 
literary work - first in his short story 'Burning Chrome' (1982) and then in the well-known science-fiction novel Neuromancer (1984)-academic research embraced the association of physical space and the digital realm.

In this chapter, I engage with digital media research through an architectural/urban viewpoint. My argument is that research on digital media does and can further benefit from socio-spatial approaches to research. The chapter will start by explaining the socio-spatial attributes of the digital realm. In the following section, I will discuss the ways in which methods and approaches of urban, environmental, and behavioral studies are being and can be further adopted for digital media and communication research. Finally, I will suggest an alternative approach-namely, considering digital spaces as places of memory - to be employed by further research on the digital realm.

\section{Socio-spatial Attributes of the Digital Realm}

Transcending simple information flows in their functioning, information, and communication technologies provides societies with the digital realm where various social interactions are realized. Even before the sprawl of social media, the social dimensions of the digital realm have been subject to many discussions. Not only are various phenomena related to digital media explained in relation to social dynamics, but social phenomena are also elaborated in relation to digital media. For example, Featherstone and Burrows explain cyberspace as an information space 'in which data is configured in such a way as to give the operator the illusion of control, movement and access to information, in which he/she can be linked together with a large number of users' $(1995$, p. 3). Although maintained through individual use, the digital realm implies collectivity and connectivity-a network of individual agents (see McBeath and Webb 2005).

Castells (2010) argues that in network societies, the logic of the space of flows prevails against the logic of the space of places. The digital realm establishes a new kind of movement through time and space that implies the flow of data and is dependent on flows rather than pauses. This flow reflects on human experience through which the human consciousness moves to witness close and distant spaces and times. Stephen Graham states that 'both urban places and electronic spaces are subject to similar processes of interlinked social struggle, as between the demands of social equity, public space and local accountability and the commodifying tendencies of global commercialization' (Graham 2005, p. 47). Accordingly, understandings of space and the social production of space are altered in the contemporary world. 
The potential of integrating a socio-spatial approach into media and communication research can be traced back to theories that account for space as being mainly socially produced. Henri Lefebvre, in The Production of Space, explains that 'a social space is constituted neither by a collection of things or an aggregate of (sensory) data, nor by a void packed like a parcel with various contents, and that it is irreducible to a "form" imposed upon phenomena, upon things, upon physical materiality', arguing that 'social space implies a great diversity of knowledge' (Lefebvre 2007, p. 27 and p. 73). The existence of a space does not solely depend on its architectural production; rather, a space needs to be experienced, adopted, and eventually produced by users for a meaningful presence. Ultimately, the digital realm owes its strength and sustainability to social involvement. It consequently resembles physical spaces in the realization of collective productions and experiences, therefore in its social production and publicness. Furthermore, diversity of information constitutes a fundamental feature of the digital realm, supporting its functioning as a social space.

It is possible to elaborate on social production in the digital realm with two approaches. First, social production is provided through new forms of communication. Social networks comprise communication and interaction tools that enable the creation of affinity among members. Peter Nieckarz states that 'it is the web of social interactions that determines the boundaries of a community and not vice versa' (2005, p. 405) and explains that internet communities are 'in many ways are not very different from non-Internet community networks in their characteristics' (Nieckarz 2005 , p. 405). The variety and quality of the personal communications in which individuals take part are thought to be sufficient for the creation of 'a sense of a community' (Rotman et al. 2009, p. 48), if not for the creation of a community. Correlatively, because the digital realm is undoubtedly public, it provides a sense of place, if not places. Or maybe, after all, 'social relations are not fixed or located in place', because 'all social relationships always involve diverse "connections", which are more or less at a distance, more or less intense, and more or less mobile' (Urry 2010, p. 144).

The digital realm also has the potential to extend to the physical space, and to mediate and increase face-to-face communication. In a study carried out by Driskell and Lyon, the respondents reported that 'the Internet has had a modestly positive impact on both increasing contact with others and communicating more with family' $(2002$, p. 385). Self-help groups are one significant example of such communication: they provide people with the support that they lack because of the unavailability of similar cases in the same locality or 
because of their drawbacks for some reason (King and Moreggi 2007). Virtual teams are another example of networks that benefit highly from communication through the internet escaping the limitations of physical space, time, and organizational boundaries, lowering travel and facility costs, reducing project schedules, and improving decision-making time (Shayo et al. 2007).

Secondly, the digital realm allows the creation and representation of cultural texts. Featherstone and Burrows (1995) point out the possibility of post-bodied form of existence, which can strengthen bodily existence in the physical public space by encouraging creativity and freedom in communication, interaction, and production. Just as Nieckarz argues, the internet 'provides a means for people to resist a centralized culture and actively create and define things on their own' $(2005$, p. 421$)$. It provides opportunities for individuals to be able to express themselves freely and to reach out for anything and anyone across the globe, contributing to the collaborative creation of social capital.

Depending on the arguments used, it is possible to assert that there is social production within the digital realm with respect to relationships among people, and between people and their physical and digital environment. The digital realm, involving collective experiences and being precisely socially produced, inherits the attributes of space.

\section{Merging the Approaches of Socio-spatial and Media RESEARCH}

Whereas it certainly is not possible to treat physical space and the digital realm as identical phenomena, depending on the socio-spatial characteristics that the digital realm possesses it is viable to merge research in both areas. Digital media in everyday life mostly operate through the visual. Jussi Parikka argues that 'the visual as part of the wider financial, urban and security regimes cannot be neglected as one fold in the topological continuum between spatial architectures and informational ones' (Parikka 2015, p. 213). Such an approach, revealing the cultural landscape of the contemporary world, superposes the virtual on the spatial. In this respect, theories and methods of socio-spatial research provide grounds for studies on the digital realm in various ways. Whereas it is not the subject of this chapter, it should be mentioned that contemporary socio-spatial research, in exchange, gets notable enhancement from media and communication research.

The digital realm, being public, encompasses social processes, which, as explained previously, designate its spatial character. Correspondingly, 
there is a growing body of research concentrating on various aspects of social production of the digital realm. Although this research often does not mention the concept of social production, it does study the formation of socio-cultural products or of communities and social groups, which almost always touch on the spaces/places of these formations. The former being related to representational spaces and the latter to social practices, these studies, which are mostly either urban or sociological, lead us to an understanding of social production-in the sense in which Lefebvre (2007) discusses the concept-within the digital realm.

As communication can be considered to be the fundamental social practice within the digital world, studies regarding people relating to each other and to information eventually provide us with insight about the social production of digital spaces. One fundamental question that is widely discussed concerning the relationship between the digital realm and people's relation to each other is the possibility of forming communities. Driskell and Lyon (2002) juxtapose three components of traditional communities: a specific place, common ties, and social interaction. For the formation of online communities the most problematic component is locality, whereas globality, rather than locality, is the essence of the digital realm. However, it is a well-established thought that online communities are possible. This viewpoint depends on the argument that social cohesion and common values take the place of geographic proximity and physical presence, consequently making relationships and communications the crucial component of society (for example, Rotman et al. 2009; Papadopoulos et al. 2012). Therefore, relationships within social networks are suitable to be analyzed as social phenomena.

One of the most prevalent areas of research in this context considers the digital realm as a public sphere in relation to democracy. The first accounts of research on the politics of the digital realm explore the potential of democracy, freedom, and access to information more on a theoretical basis (for example, Papacharissi 2002). Research on varied arenas including news media (for example, Braun and Gillespie 2011), corporate policies (Ihlen 2008), and e-government applications (for example, Bertot et al. 2010) emphasizes the significance of digital politics for the contemporary public. As could be expected, recent research discusses political issues related to specific digital agoras such as Twitter (for example, Ausserhofer and Maireder 2013) or specific cases that take place in the physical space (for example, Nanabhay and Farmanfarmaian 2011). In the work of Nanabhay and Farmanfarmaian (2011), the uprising in Tahrir 
Square in Egypt is discussed as having revealed the topological continuum between the physical space and the digital realm. Deuze, with a similar understanding of such a continuum, states that 'media are becoming invisible, as media are so pervasive and ubiquitous that people in general do not even register the presence of media in their lives' (2011, p. 143). ${ }^{1}$ As a consequence thereof, theories on social and political practices have been widely adopted in the public digital realm.

Where such theoretical frameworks of socio-spatial research are adopted, a ground for the analysis of certain formations in digital media is enabled. Lev Manovich, through referencing Michel de Certeau's influential text The Practice of Everyday Life, discusses how 'the logic of tactics has now become the logic of strategies' $(2009$, p. 324) in the media of everyday life. De Certeau (1984) refers to strategies as being of agents of power and to tactics as being of individual or group subjects. Manovich adopts this approach and integrates it into his work, explaining how, for example, companies offer customization tools in their digital products as a tactic to cover the demands of users, who would in any way develop tactics to appropriate the given products. In the light of the validity of this paradigm, it is possible to track the reflections of socio-spatial studies on research related to the development of marketing strategies or ideological and political discourses.

A number of studies on the digital realm adopt not only the theoretical framework but also the methods of environmental and behavioral research. Empirical studies of people's preferences for or behaviors in the digital realm frequently focus on the cognitive processes that guide certain practices within spaces. Intrinsically related to cognitive processes, wayfinding/navigation and cognitive/mental maps are among concepts that are inherited by digital media research from the terminology of spatial research toward the end of the 1990s. Downs and Stea explain that 'human spatial behavior is dependent on the individual's cognitive map of the spatial environment' (1973, p. 9). Cognitive/mental maps are constituted by the routes and reference points that are reflected into the mind, and are referred to for navigating within spaces. Navigation is defined as 'the act, activity, or process of finding the way to get to a place when you are travelling in a ship, airplane, car, etc.'. ${ }^{2}$ Wayfinding, on the other hand, is defined as 'the process of determining and following a path or route between an origin and a destination' (Golledge 1999, p. 6). Dahlbäck puts forward two assumptions that lie behind the use of the same methods for physical and digital spaces: geographic 
and electronic worlds are similar, and 'the activities of wayfinding and navigation are similar to the information seeking activities of users of information spaces' (Dahlbäck 1998, p. 15). Although these concepts are primarily used in studies on virtual worlds (for example, Kohler et al. 2011 ), research on wayfinding and navigation, in general, present models for better evaluating or designing the digital realm depending on human behavior (for example, Dieberger 1997; Spence 1999). In such research, the cases are handled as means of information architecture, and the patterns in the ways in which visual data guide movement are studied in various contexts and scales. The technical computational aspects of information architecture can be put aside within this chapter, and the primary subject matter can be defined as the cues present in the space of the movement and the navigational reactions of users to these cues. Here, the challenge in adopting methods of navigation research lies in the dichotomy of virtual and physical. The relevant behaviors and the entities that govern movement within physical spaces and digital spaces have different dimensionalities. Interface, which is the medium of interaction with the digital realm, and the cues involved are still two dimensional. Movement, on the other hand, is realized in a different dimension. In other words, interaction with data and movement within data are not realized in the same dimensions. Consequently, approaching with a socio-spatial point of view, the methods of spatial research on navigation and wayfinding are rendered inadequate for the digital realm. This is not because these methods do not work for the navigational aspects of behavior in the digital realm, but because they do not deal with the social aspects, which provide the required dimension for the spatiality of digital spaces.

A socio-spatial approach to media and communication research can be verified only by considering the multi-layered constitution of complex human behavior. At this point, Dourish and Chalmers's (1994) differentiation between spatial, semantic, and social forms of navigation provides an endorsement. The authors explain that although spatial models can be used for virtual environments and for digital maps of physical spaces, the systems that arrange information objects spatially and hypertext systems require semantic navigation. At the same time, they propose social navigation for the information systems that extend to collaborative activity. Such a deconstruction abides by the complexity of human behavior within both physical and digital spaces, and, in a way, reconstructs the extensive concept of spatial cognition for contemporary media, which is immensely social. 
Where we handle the digital realm as a social space, the destinations at which we arrive in our daily movement within it can be considered to be random and unexpected. Unless we search for specific information, and therefore act toward a certain destination, we are like wanderers rather than residents in the physical space. In the governance of search engines, arriving at a certain destination, finding the required information within the digital realm, is no longer a fundamental problem. For a wanderer, for a digital destination (for example, a web page, a video, a blog entry, and so on) to be reachable, links to it strongly require to be shared or promoted, and so to be connected and communicated in social media (see van Dijck 2013). The promotion of digital destinations is a subject of research on digital marketing strategies. Sharing, on the other hand, is instead realized through social tactics by users for the utilization of the digital realm. Tags and hashtags, which are for identifying and grouping data and so for making them socially accessible, constitute significant tools of navigation in both semantic and social forms. There is a growing body of research on hashtags, which elaborate on the relation between specific events, concepts, or social groups and on the hashtags used for them (for example, Romero et al. 2011). Although it has been the subject of a few social navigation-related research projects (for example, Nizam et al. 2014), the use of hashtags is yet to be explored in much more depth to understand how people behave in the digital realm.

Socio-spatial research on people's behaviors within spaces concentrates on the interrelations of individuals and social groups, and on their relations to their environment. How public spaces mediate various social acts and activities, and how people utilize and use the environmental elements, are the subject matter of socio-spatial research that handles space as a network of people and physical spatial elements. For the digital realm, hashtags provide fruitful data to be analyzed to understand these networks. They guide the researcher through the network of users and data, which corresponds to the network of people and spaces in the physical world. Although they can be subjected to debates on the ethics of research, hashtags provide relevant information about practices well accessible to the researcher. However, since data are extensively available and can be considered to be speculative, there is a need for careful analysis and elimination to ensure the validity of research.

Approaching the network of people and spaces, the subject of sociospatial research, from a broad perspective, hyper-dimensional relation building to the environment should be considered as a fundamental feature of spatial cognition. When viewed from this aspect, the conception 
of a mental image provides a rather integrative understanding of these networks in question. Based on The Image of the City by Kevin Lynch (1960), the mental image of the city can be defined as a combination of the understanding of the structure of the city, the perception of the identity of urban elements, and the meanings that people attach to spaces. Cognitive processes related to the digital realm can be explained in the light of this trilogy, which Lynch proposed to provide a holistic understanding of people's relation to their environment. Accordingly, research on the relations of people to digital spaces can be developed by studying related perceptions and meanings among navigational issues. A thorough discussion of the influence of Lynch's work on the development and research of digital visual data is provided by Orit Halpern (2015). She explains that the studies of Lynch, along with the studies of Kepes and Eames, 'contributed in complicated ways to producing perception as a channel to scale between individuated bodies and vast networks, and a pedagogy and epistemology that reworked space through a new way territory of algorithmic logics and cognitive processes' (Halpern 2015, p. 136).

Perception within the digital realm has been a popular subject for many researchers, most of whom, utilizing methodologies from environmental psychologists, explore how users perceive websites-especially corporate ones - and what makes websites usable, attractive, and engaging (for example, Wang and Li 2012). The studies in question mostly explain usability and navigation as the key features that influence people's perceptions of websites. In addition, the findings propose personalization/customization and enjoyment as features that have a positive effect on people's perceptions. These findings reveal that the formation of people's mental images of the digital realm resembles that for physical space. Consequently, it becomes expedient to suggest that adapting methods of environmental psychology research can be significantly constructive for media and communication research.

The relevant methods used in previous research involve surveys that are realized through observations of behaviors of informed subjects as well as of the object, which is the urban space, and through conducting interviews and questionnaires with a sample of respondents. In Lynch's research, for example, individuals are expected to navigate within the urban space while explaining their decisions about taking certain routes, their perceptions of and/or their emotional or evaluative approaches toward urban elements. They are also asked to respond to questions that are posed to reveal how they perceive, remember, and reflect on their experiences of the relevant 
urban spaces. Depending on the findings, he sets forth the fundamental constituents of the image of the city, and elaborates on the elements that have a strong influence on the formation of mental images to propose features of a better urban design. Kaplan et al. (1998), in parallel, utilize the data that they gather from their respondents to create a preference matrix for the design of the urban space. Although similar methods and the underlying theoretical frameworks have been adopted by a few researchers for digital media research (for example, Rosen and Purinton 2004), considering the extensive insight that is provided through such research, the adaptation and development of corresponding methods for media and communication research could be of great help both for the understanding of the network of people and the digital realm and for the design and improvement of data spaces.

\section{Approaching the Digital Realm as a Place of Memory}

These discussions designate established and developing mergers in the approaches of socio-spatial and media research. At this point, to potentially extend the scope of superposition of the virtual on the spatial, I will set forth an alternative approach to understanding the digital realm. The argument here is that media and communication research can also handle the digital realm as a place of memory.

The idea about memory's relation to place is an ancient one, since Aristotle, Cicero, and Quintilian suggested the ordering and placement of mental images within mental spaces for better remembrance. The association of individual memory with mental places is mainly established through studies of the art of memory. Frances Yates (1969) studied the art of memory, elaborating on the mnemonic practices for remembering developed by Cicero, Quintilian, and later by Matteo Ricci and Giordano Bruno. In a brief explanation, she states that 'this art seeks to memorize through a technique of impressing places and images on memory' (Yates 1969 , p. 11). Those places are not always three-dimensional ones. Yates argues that the art of memory mostly adopts architectural mnemonics and uses architectural structures to order the images of the things to be remembered. The art of memory refers to places as loci that are 'easily grasped by the memory' (Yates 1969 , p. 22), such as 'a house, an intercolumnar space, a recess, an arch, or the like', and the images are 'a figure, mark, or portrait of the object we wish to remember' (Cicero 2007, p. 44). 
Cicero (2007) highlights that there should be various loci for disposition of different groups of images and those loci should somehow be connected, as if they were the different rooms of a structure. In her study of the art of memory in different time periods, Yates makes a significant statement, and asserts that the art of memory always uses 'contemporary architecture for its memory places and contemporary imagery for its images' (1969, p. 11) and therefore has its artistic periods.

In its classic and Renaissance periods, the art of memory was the method 'of memorizing the encyclopaedia of knowledge, of reflecting the world in memory' (Yates 1969, p. 355). Later in the 17th century, the method became 'an aid for investigating the encyclopaedia and the world with the object of discovering new knowledge' (Yates 1969, p. 355) and led to the scientific method. The method indicated by the art of memory is the method of loci, which became the subject of many psychological studies to understand how the act of remembering is realized and to propose ways to practice and improve memory against an increasing number of mental disorders.

For collective memory, the art of memory is reflected in collective practices that facilitate remembering through the experience of urban spaces. In The City of Collective Memory, Christine Boyer handles cities as places of the art of collective memory: "the city [...] carries in the weaving and unravelling of its fabric the memory traces of earlier architectural forms, city plans, and public monuments' (1994, p. 31). In parallel, Aldo Rossi, in his pioneering work The Architecture of the City, states that 'the city is the locus of collective memory' (Rossi 1982, p. 130).

Hebbert (2005) focuses on streets and explains that a public space can be a locus of collective memory in two ways. First, it can operate as a memory space through its structures, monuments, symbols, and their syntax. In this way, the urban space becomes a place in which memorial and cultural texts that help societies remember are exhibited. Those cultural texts depend on contemporary technologies and ideologies. Secondly, it accommodates collective social practices and acts as a public sphere, providing a stage for public debates or gatherings (Boyer 1994, p. 7). In a similar approach, Casey (2004) sees public places as a component of public memory where a public is embodied and public interaction takes place. Boyer (1994) emphasizes this second aspect for deepening understanding of the art of collective memory. Boyer's argument is that the contemporary approach to the art of collective memory reveals a paradox in its assumption that museums are the places where the images - or the artifacts-of 
the past are to be ordered. Museums, nevertheless, are curated in such a way that those artifacts are no longer a part of spatial, temporal, or social continuity; therefore, they are not themselves socially produced, as a place would be, to become loci of collective memory. Loci of collective memory need to be accommodating collective social practices and so necessarily have to be social spaces that are collectively produced. Only in this way can they make the functioning of collective memory possible.

Where the art of memory uses contemporary architecture for its places, it is reasonable to consider the digital realm as a locus for contemporary collective memory. If the art of memory aims at remembering better, the contemporary art of collective memory, to which digital media is integral, aims at articulation. The digital realm offers places for the ordering and imprinting of digital images - places that are socially produced, and are not at all more virtual than the mental places of the art of memory. In other words, the digital realm has the potential to operate as a locus where images, 'forms, marks or simulacra of what we wish to remember' (Yates 1969, p. 22), are placed. The strength of the digital realm as a locus of memory is based on its features that make it a social space: its publicness and accessibility, its social production, and so its integration into daily life. Cicero (2007), for individual rhetorical memory, explains that conscious organization of images in significant places is required. The digital realm, then, can be evaluated and developed through architectural mnemonics considering its organization as a socially produced space where articulation is to be made possible. Although architectural mnemonics is not an extrinsic concept for virtual worlds, the research on the digital realm in its broadest context and also on specific digital spaces can further benefit from this method.

As better remembering depends on the encoding and organization of information through order, orientation, grouping, association, affect, and repetition, a combination of the theoretical grounds and methods discussed in the previous part of the chapter eventually reflects the principles of the art of memory. In fact, these principles are all very well handled and explored by the agents involved in the construction and development of digital infrastructures. The techniques of better remembering can further be utilized to develop guidelines for the design of digital spaces. Research on digital spaces, on the other hand, can embrace inclusive methods considering the aspects mentioned together for the understanding of the audience's use and experience of certain digital spaces. In this way, criteria regarding analysis in relevant academic research as well as efforts to ensure articulation of websites, services, or portals can be based on solid grounds and be systematized. This approach does not necessarily suggest the use of alternative methods 
for media and communication; however, it proposes an alternative disposition that would help cope with the dichotomy of the physical and the virtual in the potential adoption of methods of socio-spatial research.

\section{Conclusion}

The objective of this chapter was to provide an overview of studies integrating socio-spatial approaches into digital media research, and to elaborate on how the methods of media and communication research can be enriched with socio-spatial approaches. The basis of this disposition is built on the line of reasoning that the digital realm inherits a number of sociospatial attributes of physical spaces. Architectural and urban studies have long been nourished by the acknowledgment of space as being socially produced. As a fundamental feature of contemporary digital media, social production of the digital realm is realized through social practices and representational spaces, which are both proposed by Lefebvre (2007) as components of social spaces. Consequently, various issues related to physical spaces can be observed in the digital realm, leading us to consider the digital realm as a social space in research.

There is a body of research that focuses either on the cognitive processes or on the social processes within the digital realm. Studies on cognitive processes are related to the ways in which people experience and perceive the digital realm, and adopt various methods of environmental and behavioral studies. On the other hand, works on questions of social processes question or explore how people form communities or cultural texts that are traditionally accepted to be closely related to the spaces in which they are formed. I believe that an overview of these studies can explain and inspire merging of the approaches of socio-spatial and media research.

In the last part of the chapter, to extend the scope of superposition of the virtual on the spatial for further research, I discuss the potential of approaching the digital realm as a place of memory. This potential is originated again on the spatiality of the digital realm. As the digital realm embraces acts, tools, and objects of remembering just like physical spaces do, such an integrative approach paves the way for evaluating and developing the digital realm for better articulation of digital spaces and therefore for better functioning of digital life, which is integral to contemporary daily life. The discussion of socio-spatial approaches in this chapter aims at encouraging the use and development of innovative methods for media and communication research, and also at paving the way for comprehending the significant influence of media on spatial practices for socio-spatial research. 


\section{Notes}

1. For a critique of Mark Deuze's argument, see Kubitschko and Knapp (2012).

2. See Navigation, in Merriam-Webster dictionary; http://www.merriamwebster.com/dictionary/navigation (accessed 10 January 2016).

\section{REFERENCES}

Ausserhofer, J. and Mairede, A. (2013) National Politics on Twitter. Information, Communication \& Society 16(3): 291-314.

Bertot, J., Jaeger, P. and Grimes, J. (2010) Using ICTs to Create a Culture of Transparency: E-government and Social Media as Openness and Anti-corruption Tools for Societies. Government Information Quarterly 27(3): 264-71.

Boyer, M. (1994) The City of Collective Memory: Its Historical Imagery and Architectural Entertainments (Cambridge, MA: MIT Press).

Braun, J. and Gillespie, T. (2011) Hosting the Public Discourse, Hosting the Public. Journalism Practice 5(4): 383-98.

Casey, E. (2004) Public Memory in Place and Time. In: K. Phillips (Ed.), Framing Public Memory (Tuscaloosa: University of Alabama Press), pp. 17-44.

Castells, M. (2010) The Rise of the Network Society. The Information Age: Economy, Society and Culture. Vol. 1 (Oxford: Blackwell).

Cicero (2007) From Ad Herennium. In M. Rossington and A. Whitehead (Eds.), Theories of Memory: A Reader (Edinburgh: Edinburgh University Press), pp. 43-9.

Dahlbäck, N. (1998) On Spaces and Navigation in and Out of the Computer. In N. Dahlbäck (Ed.), Exploring Navigation: Towards a Framework for Design and Evaluation of Navigation in Electronic Spaces (Kista, Sweden: SICS), pp. 15-29.

De Certeau, M. (1984) The Practice of Everyday Life (Berkeley: University of California Press).

Deuze, M. (2011) Media Life. Media, Culture \& Society 33(1): 137-48.

Dieberger, A. (1997) Supporting Social Navigation on the World Wide Web. International Journal of Human Computer Studies 46(6): 805-25.

Dourish, P. and Chalmers, M. (1994) Running out of Space: Models of Information Navigation. Human Computer Interaction Conference, HCI 94 (Glasgow).

Downs, R. and Stea, D. (1973) Cognitive Maps and Spatial Behaviour: Process and Products. In: R. Downs and D. Stea (Eds.), Image and Environment: Cognitive Mapping and Spatial Behavior (Chicago: Aldine Press), pp. 8-26.

Driskell, R. and Lyon, L. (2002) Are Virtual Communities True Communities? Examining the Environments and Elements of Community. Citye Community 1(4): 373-90. 
Featherstone, M. and Burrows, R. (1995) Cultures of Technological Embodiment: An Introduction. In: M. Featherstone and R. Burrows (Eds.), Cyber Space/ Cyber Bodies / Cyber Punk: Cultures of Technological Embodiment (London: Sage), pp. 1-20.

Golledge, R. (1999) Human Wayfinding and Cognitive Maps. In R. G. Golledge (Ed.), Wayfind Behavior: Cognitive Mapping and Other Spatial Processes (Baltimore: Johns Hopkins University Press), pp. 5-45.

Graham, S. (2005): Imagining the Real-Time City: Telecommunications, Urban Paradigms and the Future of Cities. In: S. Westwood and J. Williams (Eds.), Imagining Cities: Scripts, Signs, Memory (London: Routledge), pp. 31-47.

Halpern, O. (2015) Beautiful Data: A History of Vision and Reason Since 1945 (Durham: Duke University Press).

Hebbert, M. (2005) The Street as a Locus of Collective Memory. Environment and Planning D 23(4): 581-96.

Ihlen, Ø. (2008) Mapping the Environment for Corporate Social Responsibility. Corporate Communications: An International Journal 13(2): 135- 46.

Kaplan, R., Kaplan, S. and Ryan, R. (1998) With People in Mind: Design and Management of Everyday Nature (Washington, DC: Island Press).

King, S. and Moreggi, D. (2007) Internet Self-Help and Support Groups: The Pros and Cons of Text-Based Mutual Aid. In: J. Gackenbach (Ed.), Psychology and the Internet: Intrapersonal, Interpersonal, and Transpersonal Implications (Boston: Elsevier), pp. 221-44.

Kohler, T., Fueller, J., Matzler, K., et al. (2011) Co-Creation in Virtual Worlds: The Design of the User Experience. MIS Quarterly 35(3): 773-88.

Kubitschko, S. and Knapp, D. (2012) An Invisible Life? A Response to Mark Deuze's 'Media Life'. Media, Culture é Society 34(3): 359-64.

Lefebvre, H. (2007) Production of Space (Oxford: Wiley-Blackwell).

Lynch, K. (1960) The Image of the City (Cambridge, MA: MIT Press).

Manovich, L. (2009) The Practice of Everyday (Media) Life: From Mass Consumption to Mass Cultural Production? Critical Inquiry 35(2): 319-31.

McBeath, G. and Webb, S. (2005) Cities, Subjectivity and Cyberspace. In: S. Westwood and J. Williams (Eds.), Imagining Cities: Scripts, Signs, Memory (London: Routledge), pp. 249-60.

Nanabhay, M. and Farmanfarmaian, R. (2011) From Spectacle to Spectacular: How Physical Space, Social Media and Mainstream Broadcast Amplified the Public Sphere in Egypt's 'Revolution'. The Journal of North African Studies 16(4): 573-603.

Nieckarz, P. (2005) Community in Cyber Space? The Role of the Internet in Facilitating and Maintaining a Community of Live Music Collecting and Trading. City \& Community 4(4): 403-23.

Nizam, N., Watters, C. and Gruzd, A. (2014) Link Sharing on Twitter During Popular Events: Implications for Social Navigation on Websites. In: System Sciences, 47th Hawaii International Conference on System Science (HICSS), pp. 1745-54. 
Papacharissi, Z. (2002) The Virtual Sphere: The Internet as a Public Sphere. New Media \& Society 4(1): 9-27.

Papadopoulos, S., Kompatsiaris, Y., Vakali, A., et al. (2012) Community Detection in Social Media. Data Mining and Knowledge Discovery 24(3): 515-54.

Parikka, J. (2015) The City and the City: London 2012 Visual (Un)Commons. In: D. M. Berry and M. Dieter (Eds.), Postdigital Aesthetics: Art, Computation and Design (Basingstoke: Palgrave Macmillan), pp. 203-18.

Romero, D., Meeder, B. and Kleinberg, J. (2011) Differences in the Mechanics of Information Diffusion Across Topics: Idioms, Political Hashtags, and Complex Contagion on Twitter. In: Proceedings of the 20th International Conference on World Wide Web (Hyderabad, India), pp. 695-704.

Rosen, D. and Purinton, E. (2004) Website Design: Viewing the Web as a Cognitive Landscape. Journal of Business Research 57(7): 787-94.

Rossi, A. (1982) The Architecture of the City (Cambridge, MA: MIT Press).

Rotman, D., Golbeck, J. and Preece, J. (2009) The Community is Where the Rapport Is - On Sense and Structure in the YouTube Community. In: Proceedings of the Fourth International Conference on Communities and Technologies, pp. 41-50.

Shayo, C., Olfman, L., Iriberri, A. and Igbaria, M. (2007) The Virtual Society: Its Driving Forces, Arrangements, Practices, and Implications. In: J. Gackenbach (Ed.), Psychology and the Internet: Intrapersonal, Interpersonal, and Transpersonal Implications (Boston: Elsevier), pp. 187-219.

Spence, R. (1999) A Framework for Navigation. International Journal of Human Computer Studies 51(5): 919-45.

Urry, J. (2010) Connections. In: G. Bridge and S. Watson (Eds.), The Blackwell City Reader. 2nd ed. (Malden: Wiley-Blackwell), pp. 144-51.

van Dijck, J. (2013) The Culture of Connectivity: A Critical History of Social Media (Oxford: Oxford University Press).

Wang, W.-T. and Li, H.-M. (2012) Factors Influencing Mobile Services Adoption: A Brand-equity Perspective. Internet Research 22(2): 142-79.

Yates, F. (1969) The Art of Memory (Harmondsworth: Penguin). 